\title{
REGENERATIVE BRAKING OF A LINEAR INDUCTION MOTOR USED FOR THE TRACTION OF A MAGLEV VEHICLE
}

\author{
Roberto André Henrique de Oliveira ${ }^{1}$, Laércio Simas Mattos ${ }^{2}$, Antônio Carlos Ferreira ${ }^{1}$, \\ Richard Magdalena Stephan ${ }^{1}$ \\ ${ }^{1}$ Universidade Federal do Rio de Janeiro - UFRJ - Rio de Janeiro/RJ, Brazil \\ ${ }^{2}$ Centro Federal de Educação Tecnológica de Minas Gerais - CEFET - MG - Leopoldina/MG, Brazil \\ e-mails: raholiveira@ufrj.br, laercio@leopoldina.cefetmg.br, ferreira@coep.ufrj.br, richard@dee.ufrj.br
}

\begin{abstract}
This paper presents the analysis and results obtained with the regenerative braking technique applied to the linear induction motor used for the traction of MagLev-Cobra, an urban transportation vehicle. The motor, with a special geometry, the converter, with bidirectional power flow, and the drive control are reported. An improvement on the motor secondary side was proposed and tested. Traction an attraction forces are measured. An analytical development showed the optimal velocity profile for regenerative braking. Finally, experimental results validated the analyses and showed the weakness of tests on a small track.
\end{abstract}

Keywords - Linear Induction Motor (LIM), Regenerative Braking, Scalar Control.

\section{LIST OF SYMBOLS}

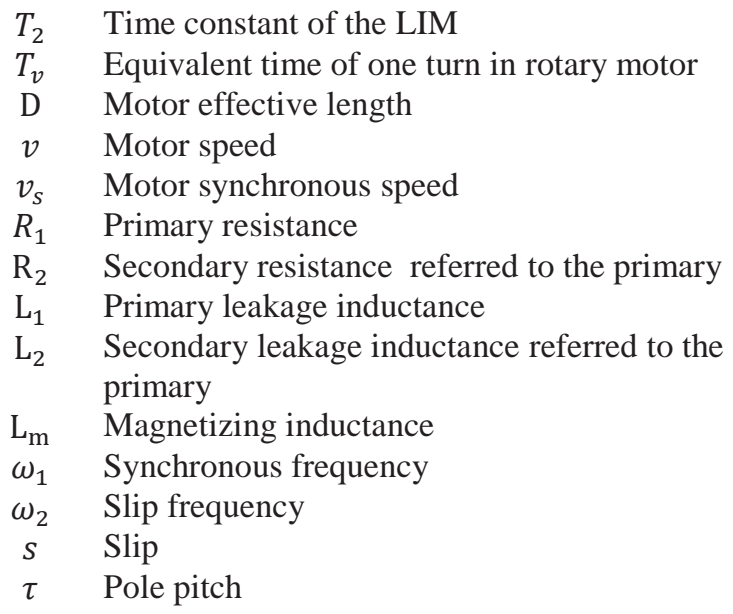

\section{INTRODUCTION}

Nowadays, $50 \%$ of the world population live in cities and by 2050 this percentage will reach $70 \%$ [1]. This reality creates the need for efficient energy utilization and development of sustainable technologies. Transporting the growing urban population between and inside megacities is a major challenge that cannot be fulfilled with conventional means.

Driven by these demands, UFRJ (Universidade Federal do Rio de Janeiro) has been developing since 2000 a vehicle for

"Manuscript received 29/01/2014; revised 07/04/2014; accepted for publication 19/08/2014, by recommendation of the Special Section Editor Mário L. da S. Martins." urban transportation called MagLev-Cobra, shown in Figure 1 [2]-[4].

The MagLev-Cobra technology proposes a magnetically levitated vehicle with multiple short units, allowing curves of small radius, ramps of $10 \%$ and velocities up to $70 \mathrm{~km} / \mathrm{h}$. When these short units are connected, the vehicle resembles a 'snake' or 'cobra' in Portuguese. Since the noise level is low, the vehicle can run inside cities on elevated structures. The estimated construction costs are $1 / 3$ of that necessary for subways. The levitation technology is based on the flux pinning property of High Temperature Superconductor (HTS) blocks of Y-Ba-Cu-O and the magnetic field of NdFe-B magnets [5], [6]. These materials were available only at the end of last century and until today there is no such system industrialized or in commercial use.

Contributing to the environmental friendly characteristics, the vehicle will operate with a regenerative braking system able to convert kinetic energy into electricity. The energy regeneration is a usual concept applied in several areas of engineering. Recently, Tavares et al. [7], [8], Yu et al. [9], Teramoto et al. [10] published results on regenerative braking in conventional trains driven by linear motors.

Following this technological trend, this article will present the energy regeneration with the linear induction motor (LIM) used for the traction of MagLev-Cobra.

Besides the application to an innovative transportation system, this paper contributes with the analysis and improvements of a new linear motor [11], which geometry increases the levitation force, as described in section III.

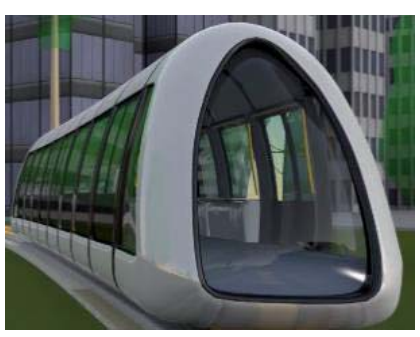

(a)

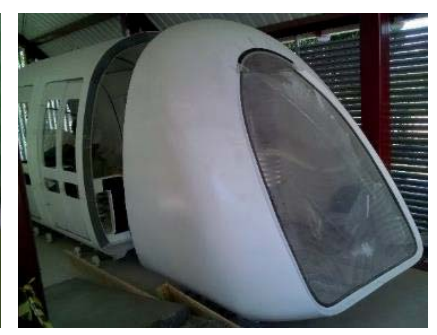

(b)
Fig. 1 MagLev-Cobra. (a) Illustration. (b) Prototype.

\section{THE MAGLEV-COBRA VEHICLE}

This vehicle was originally conceived in 2000 [12] and a small scale prototype was concluded in 2004 [13]. The initial efforts for the construction of a full scale functional prototype were reported in 2008 [14], [15], but only in 2012, with funding from Banco Nacional de Desenvolvimento Econômico e Social (BNDES) and Fundação de Amparo à 
Pesquisa do Estado do Rio de Janeiro (FAPERJ), the construction of the full scale prototype could have been started. This electric and levitating vehicle, impelled by a linear induction motor, will connect two blocks of the Center of Technology inside the University campus. The vehicle will cover the $200 \mathrm{~m}$ distance in one minute on an elevated line, built in lightweight and easy to install metal structures shown in Figures 2.a and 2.b.

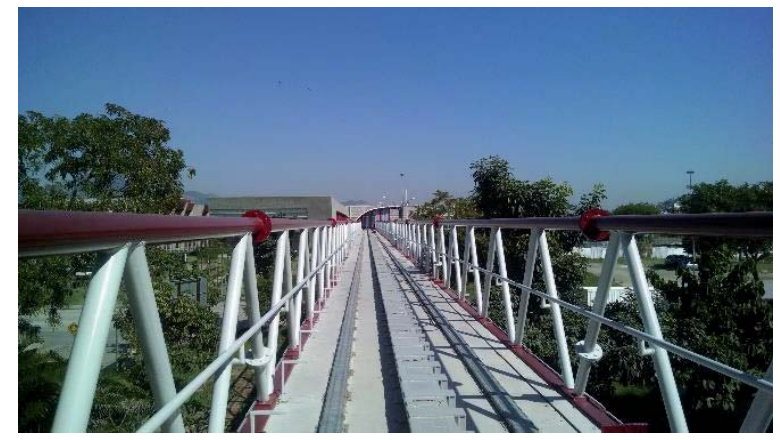

(a)

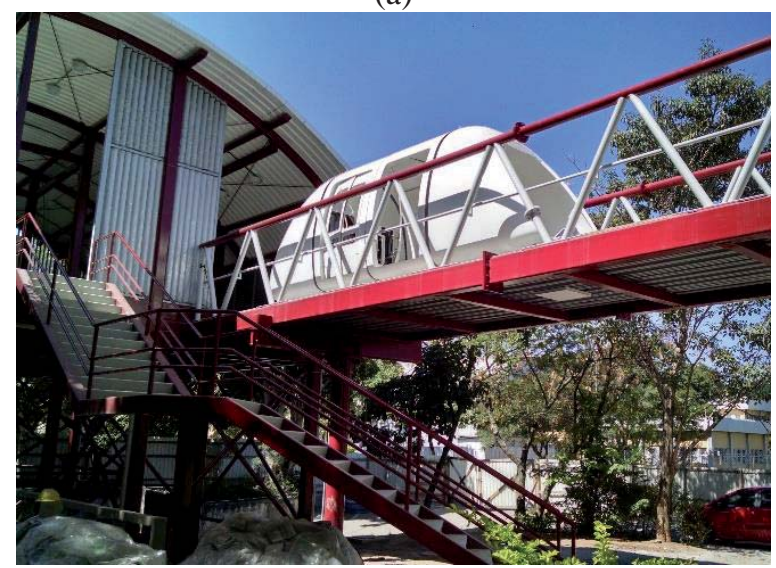

(b)

Fig. 2 MagLev-Cobra. (a) Elevated track. (b) Station construction.

\section{LINEAR INDUCTION MOTOR (LIM)}

\section{A. Description}

The linear induction motor (LIM) allows the displacement of a load in a longitudinal direction without gears, pulleys, or other mechanical mean. The magnetic flux in the LIM is longitudinal, that is, the magnetic flux lines are parallel to the direction of the travelling magnetic field [8], [16], [17].

The main parts of a LIM are:

- Primary side, that contains the phase windings and receives the energy supply.

- Secondary side, made by laminated iron and short-circuited conducting bars, similar to a squirrel cage rotor.

The MagLev-Cobra uses a LIM of short primary and long secondary. The number of primary modules depends on the total length of the vehicle and the prototype under construction will use two primaries is designed to use a primary with two modules. The low manufacturing cost of this choice makes it financially viable. The project generated a patent [11] by presenting a different LIM geometry, as shown in Figure 3. With this new format, the attraction force that exists between primary and secondary will contribute to the levitation force as is discussed in section VI. This configuration differs from other proposals [18],[20].

There are different methods to supply current to the primary, for instance, collecting brushes, energy transfer by induction or ultra-capacitors. The present study applies the first method [16], [17].

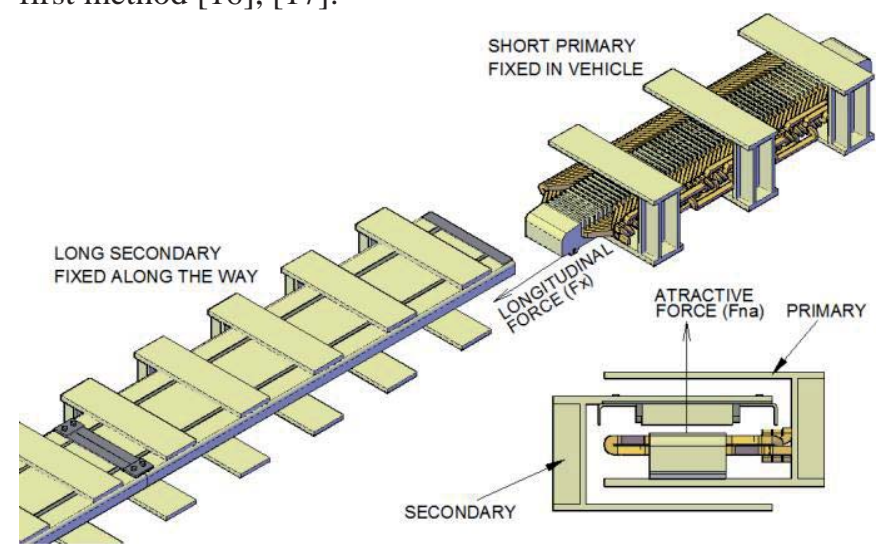

Fig. 3. Linear Induction Motor.

\section{B. Model}

Duncan (1983) developed the equivalent circuit of LIM, as shown in Figure 4 [21], [22]. The dimensionless parameter $Q$ indicates the end effects influence on the traditional model of a rotating induction motor and depends on the motor construction. $D$ is the effective length of the motor primary defined by $(P+1 / 3) \tau$, where $\mathrm{P}$ is the number of poles and $\tau$ the pole pitch (Figure 5). This definition of effective motor length is valid for low speeds $(v \leq 20 \mathrm{~m} / \mathrm{s})$, according to [21]. The total motor length is $(P+2 / 3) \tau$, shown in Figure 6 for the six poles motor. The time constant $\left(\mathrm{T}_{2}\right)$ of the LIM inductive circuit and the time $\left(\mathrm{T}_{v}\right)$ are defined in (1)(3) where $v$ is motor speed.

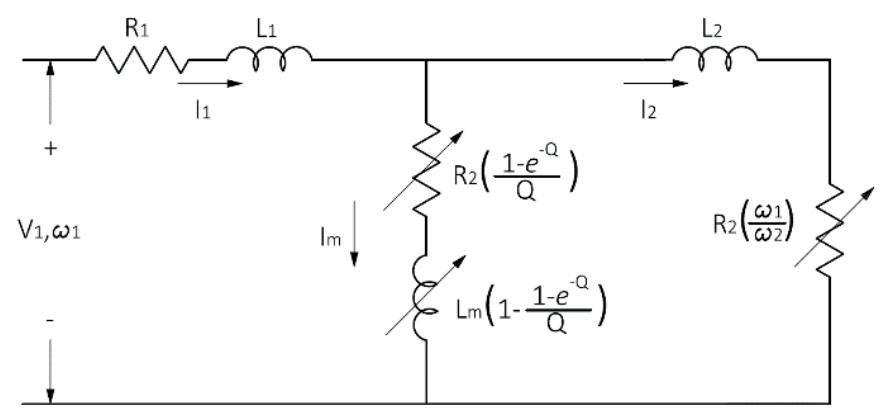

Fig. 4. LIM equivalent circuit.

$$
\begin{gathered}
T_{2}=\left(L_{m}+L_{2}\right) / R_{2} \\
T_{v}=\frac{D}{v} \\
Q=T_{v} / T_{2}=\left(D R_{2}\right) /\left(v\left(L_{m}+L_{2}\right)\right) \\
B(x, t)=B_{\max } \sin \left[\omega t-\frac{\pi}{\tau} x\right] \\
v_{s}=2 \tau f \\
s=\frac{v_{s}-v}{v_{s}}
\end{gathered}
$$




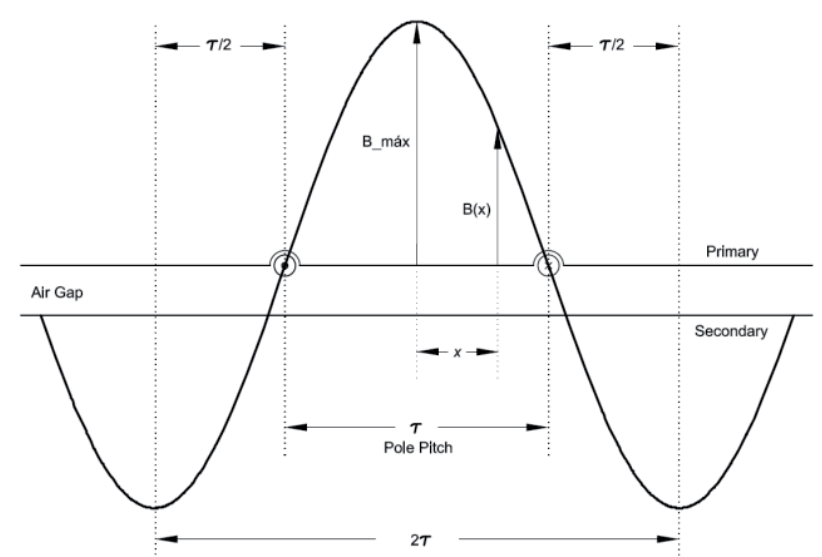

Fig. 5. Traveling Field.

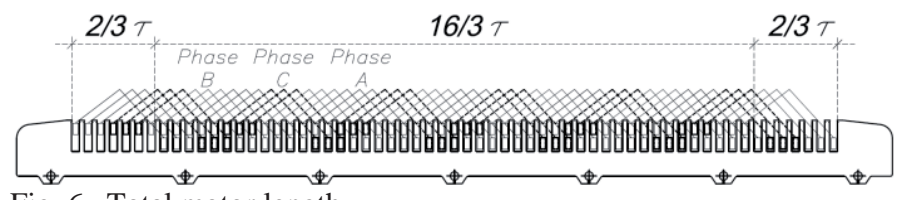

Fig. 6. Total motor length.

\section{TRACTION FORCE}

The LIM develops a force in the longitudinal direction $\left(F_{x}\right)$, responsible for the movement, and a force $\left(F_{n}\right)$ in the normal direction. The traction force $F_{x}$ is generated by the interaction between the induced current in the secondary with the travelling field in the air gap. The total electromagnetic power developed by the motor $\left(P_{A G}\right)$ can be calculated from the equivalent circuit and (6). The power effectively converted to mechanical form $\left(P_{\text {conv }}\right)$ should consider the ohmic losses in the secondary.

$$
P_{A G}=\frac{3 I_{2}^{2} R_{2} \omega_{1}}{\omega_{2}} .
$$

According to Chapman [23], the force $F_{x}$ is given by:

$$
F_{x}=\frac{P_{C o n v}}{v}
$$

The measurement system shown in Figure 7 was used to obtain experimental data and validate the model. Figure 7.a shows the arrangement with a load cell fixed in a rigid base through steel cables, the display is also shown in this figure.

A $2000 \mathrm{~kg}$ load cell was used (Figure 7.b) to measure forces. The anchoring of the motor primary with the cable is shown in Figure 7.c.

Tests were performed with the primary blocked for different air gaps and keeping the ratio V/f constant, as shown in TABLE I. The results for air gaps between $8 \mathrm{~mm}$ and $20 \mathrm{~mm}$ are shown in Figures 8.a and 8.b.

The motor secondary consists of modular sections of $1.5 \mathrm{~m}$ length, mechanically connected side by side along the line. During the tests, a malfunction when the primary passed under secondary junctions was noted. The secondary modular sections are united by painted metallic plates, screwed on their housing (Figure 9). At these junction points, current sags were observed, which result in momentary force loss.

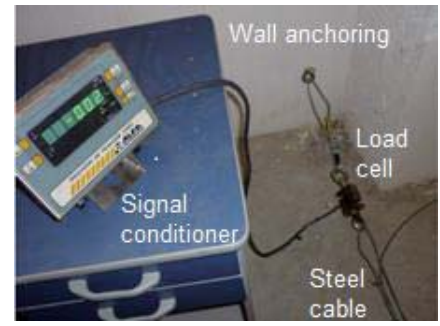

(a)

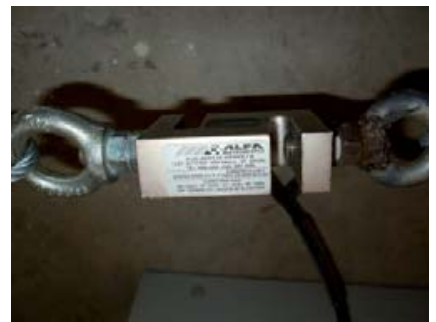

(b)

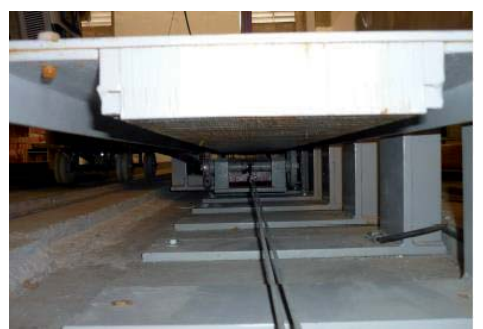

(c)

Fig. 7. Traction force measurement: (a) arrangement, (b) load cell and (c) connection to the primary.

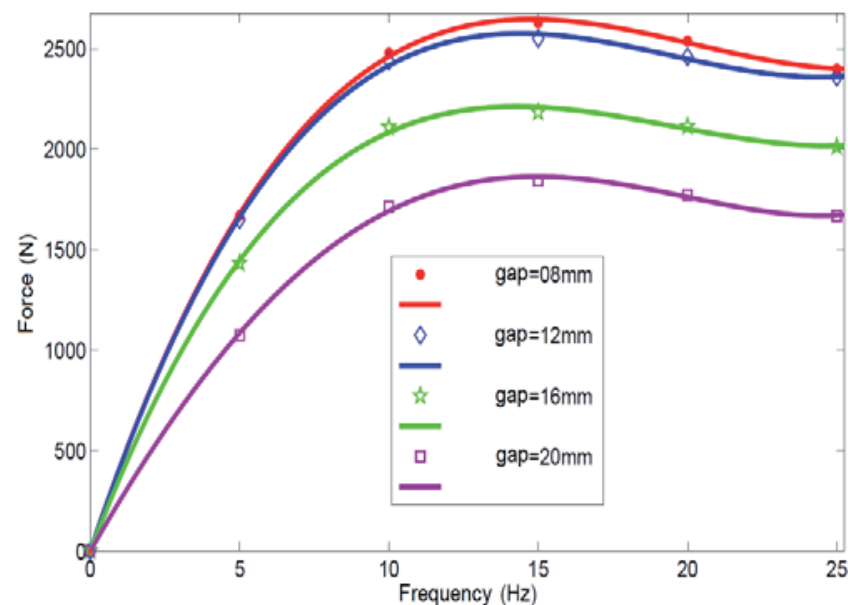

(a)

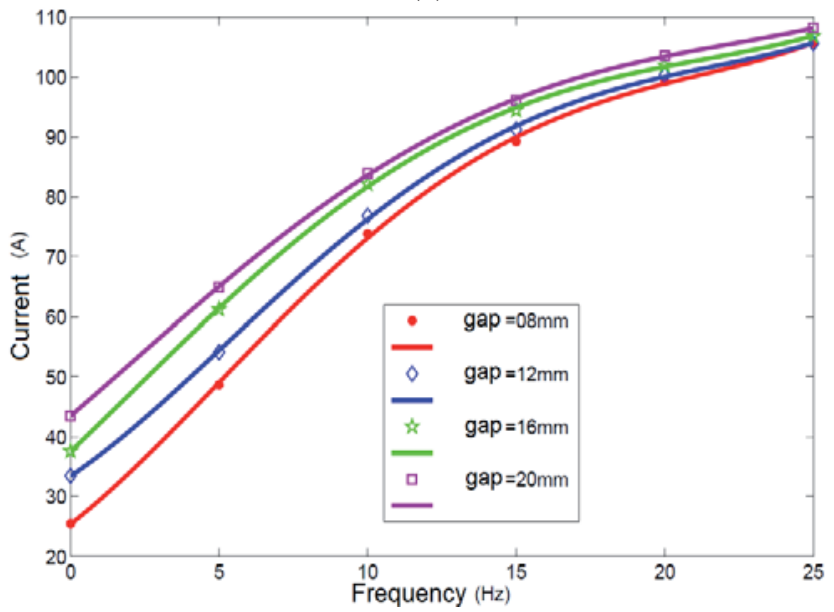

(b)

Fig. 8. Force and current measurements: (a) $F x f$ and (b) $I x f$. 

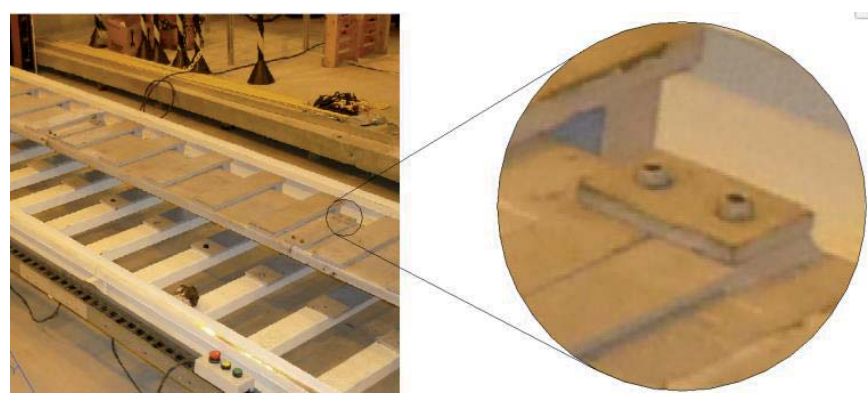

Fig. 9. Mechanical coupling between secondary modules.

TABLE I

V/f constant.

\begin{tabular}{ccc}
\hline $\mathbf{V}[\mathbf{V}]$ & $\mathbf{F}[\mathbf{H z}]$ & $\mathbf{V} / \mathbf{f}[\mathbf{V} / \mathbf{H z}]$ \\
\hline 085 & 05 & 17.0 \\
165 & 10 & 16.5 \\
245 & 15 & 16.3 \\
320 & 20 & 16.0 \\
390 & 25 & 15.7 \\
\hline
\end{tabular}

Figure 10 shows a current profile when a primary passes through two connections. Trying to minimize this issue, an electrical connection between the secondary sections was provided with aluminum bars, as shown in (Figure 11). In order to verify the influence of the electrical connection on the motor behavior, traction force measurements were repeated for the three configurations presented in Figure 12.

Figure 13 shows the improvement. The force curve with electric connection (marker ' + ') lies between the curve without electric connection (marker 'o') and the ideal condition of continuous secondary (marker ' $*$ '), obtained when the primary is exactly over a secondary module.

Figure 14 shows the corresponding currents. The results also show that the magnetic gap between the secondary modules has an influence that could not be compensated.

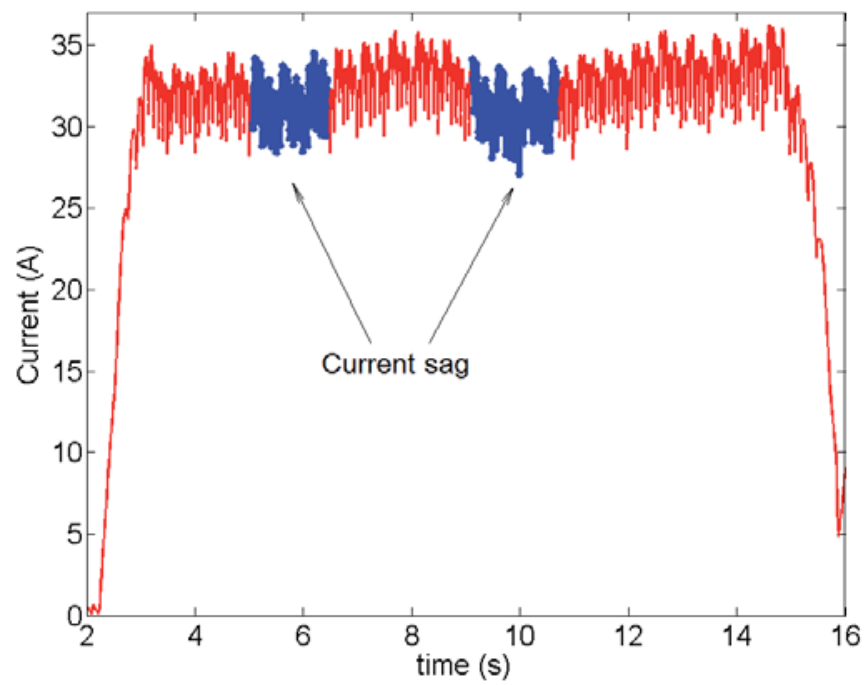

Fig. 10. Current $\left(I_{1}\right)$ behavior in the transition between secondary parts (current sag).

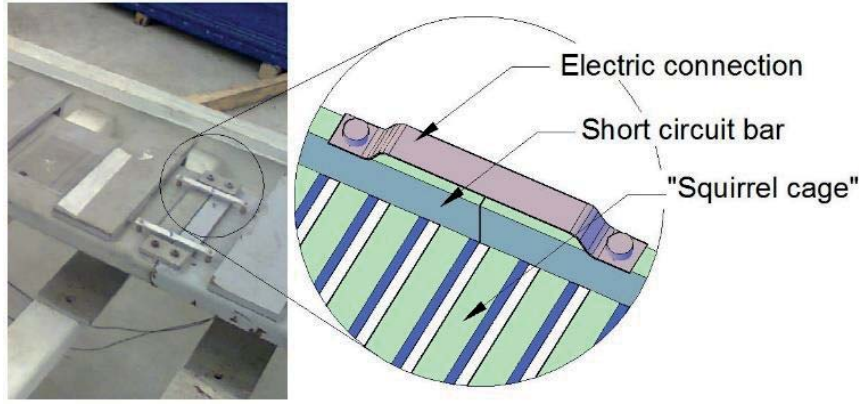

Fig. 11. Electric connection between secondary sections.

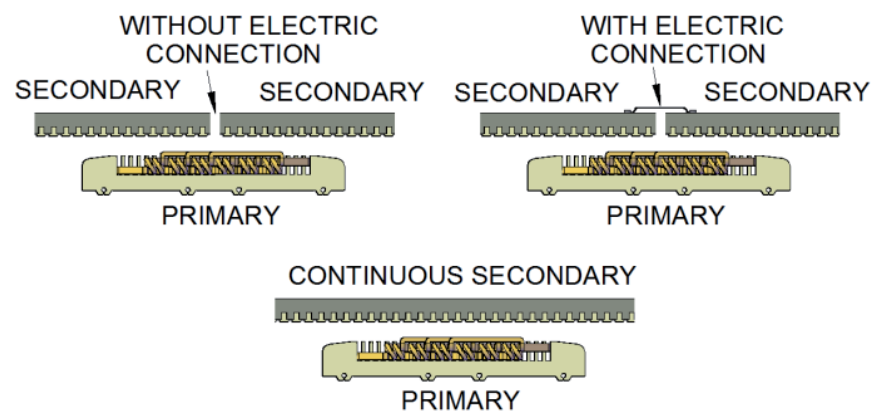

Fig. 12. Primary and secondary position during test.

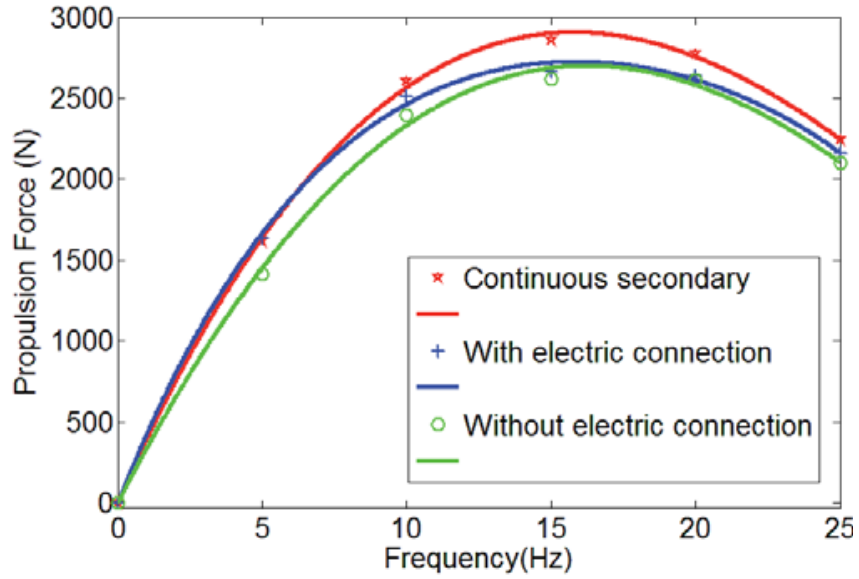

Fig. 13. Propulsion force with "cage" continuous and discontinuous.

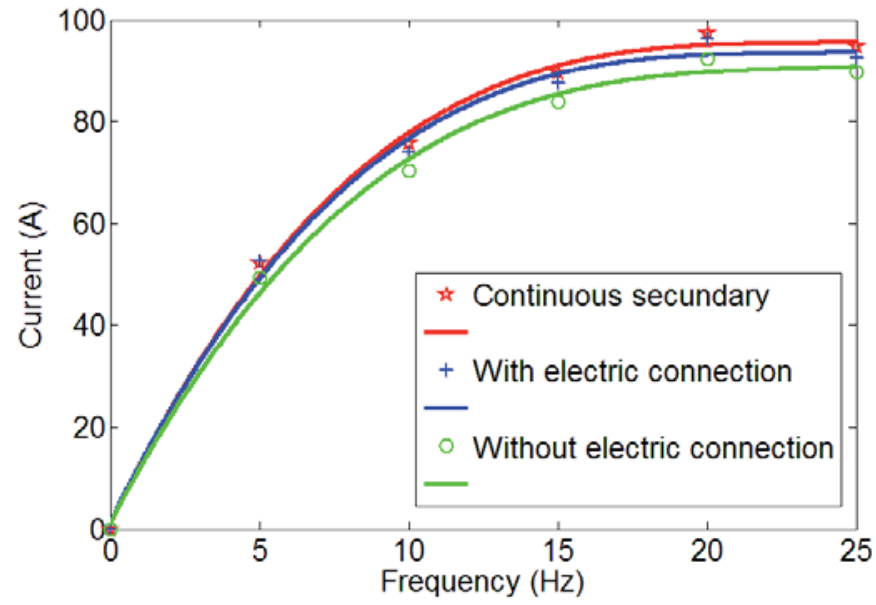

Fig. 14. Currents with "cage" continuous and discontinuous. 


\section{ATTRACTION FORCE}

The normal force $F_{n}$ existing in the LIM is the result of the magnetic flux crossing the air gap and has two components. The first component $F_{n a}$ is the electromagnetic attractive force between the primary and the secondary iron core and the second component is the electro dynamic repulsion force $F_{n r}$ between the moving primary and secondary Magneto Motriz Force (MMF). The repulsive force $F_{n r}$ can be disregarded because the vehicle operates at low speed [24].

For this test, the longitudinal movement is blocked by a steel cable anchored in the wall. The attraction force is measured by installing a load cell between the floor and the primary of the linear motor. The test adopted the air gap of $8 \mathrm{~mm}$. The frequency was varied between $1 \mathrm{~Hz}$ to $7 \mathrm{~Hz}$ and the $V / f$ ratio was kept constant. The arrangement for the measurements is shown in Figure 15. The attractive force reaches approximately 3000 N, as can be seen in Figure 16.

Figure 17 shows that the force remained constant between $3 \mathrm{~Hz}$ and $6 \mathrm{~Hz}$, because the $F_{n a}$ force is proportional to the square of magnetic field $(B)$, but the magnetic field is proportional to the ratio V/f (according to (8) [24]).

$$
F_{n a}=-\frac{1}{\mu_{0}}|B|^{2} A \therefore B \sim \frac{V}{f}
$$

where, $\mu_{0}$ is air magnetic permeability and $A$ is area (constant).

When the frequency is low, between $1 \mathrm{~Hz}$ and $3 \mathrm{~Hz}$, resistance $R_{l}$ is significant. Above $6 \mathrm{~Hz}$ the impedance $j \omega_{1} L_{1}$, corresponding to the flux leakage, plays an important role and the force decreases.

$$
\begin{gathered}
e_{1}=k_{w} N_{1} \frac{d}{d t} \phi_{m} \cos \left(\omega_{1} t\right) \\
=-\omega_{1} k_{w} N_{1} \phi_{m} \sin \left(\omega_{1} t\right) \\
\sqrt{2} \pi k_{w} N_{1} \phi_{m} \approx \frac{V_{1}}{f_{1}}=\text { const }
\end{gathered}
$$

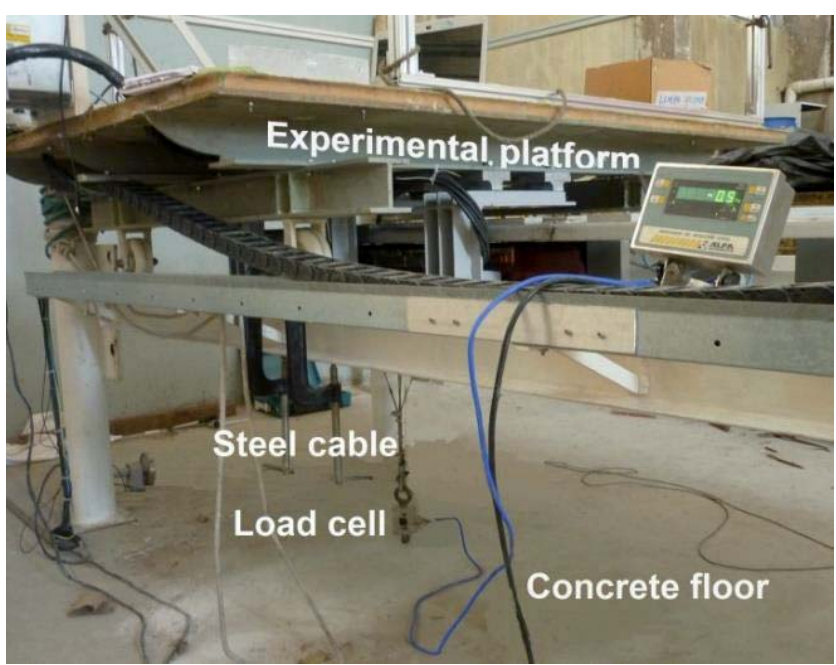

Fig. 15. Arrangement for attractive forces tests.

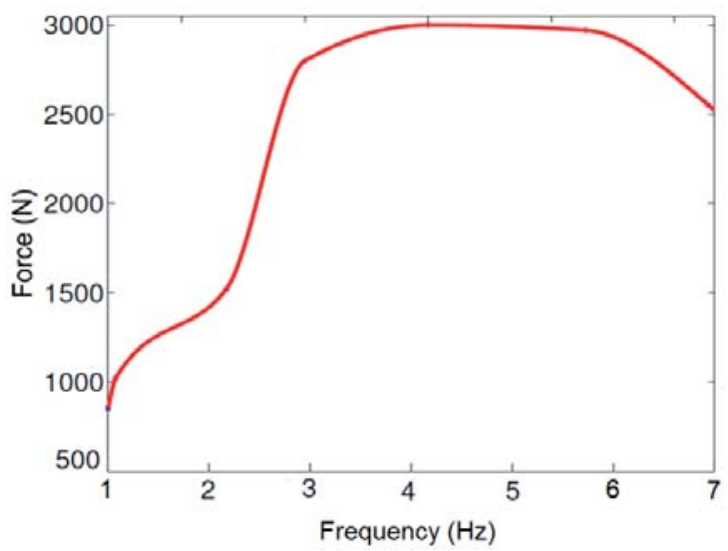

Fig. 16. Net Attraction Force; air gap $=8 \mathrm{~mm} ; \mathrm{M}=450 \mathrm{~kg}$.

\section{V/F CONTROL}

Linear induction motors can be controlled by many techniques of frequency variations, classified as [23], [25]:

- $\quad$ Direct Torque and Force Control (DTFC);

- Stator Flux Vector Control;

- Rotor Flux Vector Control;

- V/f Scalar Control.

The $V / f$ scalar control was adopted in the experiments presented in this paper due to its simplicity, since no speed sensor or accurate speed estimation is necessary for the operation of the MagLev-Cobra vehicle. This kind of control presents a satisfactory response when the operation does not require a fast speed variation.

By Faraday's Law, the voltage induced in the primary winding is given by (9). Equation (10) shows that if the relation $V / f$ is constant the flux is constant too [16]. The $V / f$ open loop control strategy is shown in Figure 17.

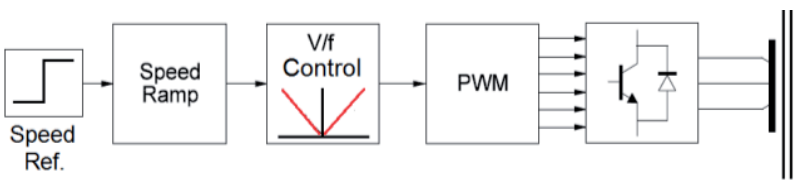

Fig. 17. V/f scheme.

\section{BIDIRECTIONAL POWER CONVERTER}

A bidirectional power converter drives the three-phase linear induction motor shown in Section III. A three-phase transformer connected in $\operatorname{delta}(\Delta)$, with line voltage 380 Vac@60 Hz supplies the system. The bidirectional power converter layout used on MagLev-Cobra (Figure 18) has a capacitor preload circuit composed of a diode bridge (DR1) and a resistor bank.

After the DC bus voltage reaches its steady state, DR1 and preload resistors are bypassed. The power flows from CFW11-105-RB to CFW11-88A frequency inverters, that feed each motor. With this topology, a variable number of inverters can be connected to the DC bus. The CFW11-105$\mathrm{RB}$ converter has the capacity to regenerate energy during braking [25]-[27]. 
Figure 19 shows a picture of the bidirectional power converter and its components. The CFW11-88A inverters are installed inside the vehicle.

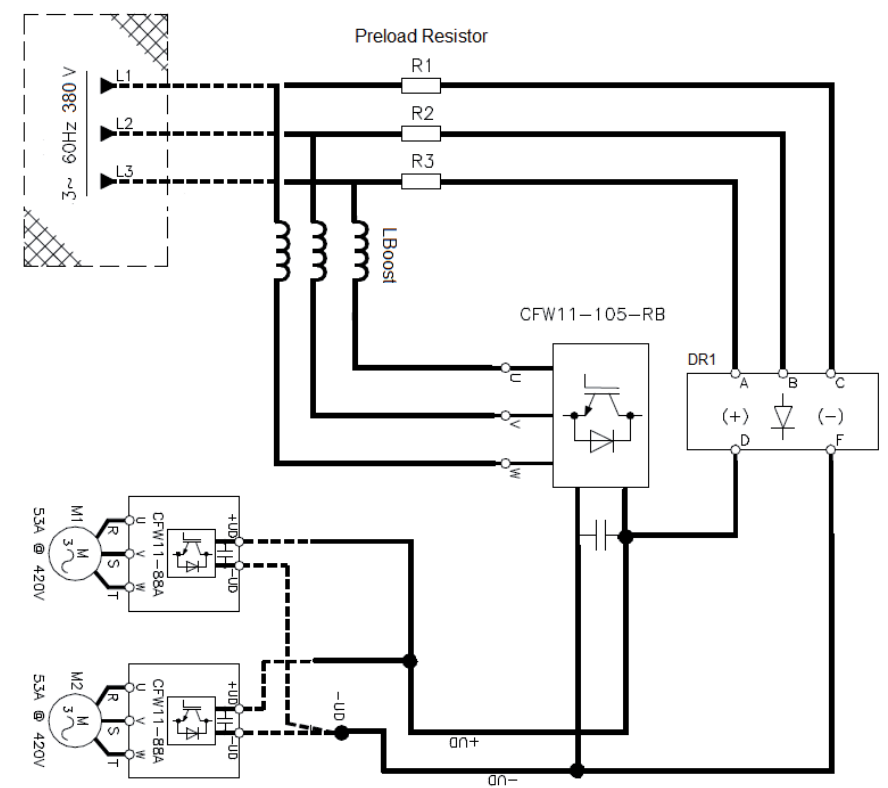

Fig. 18. Bidirectional power converter.

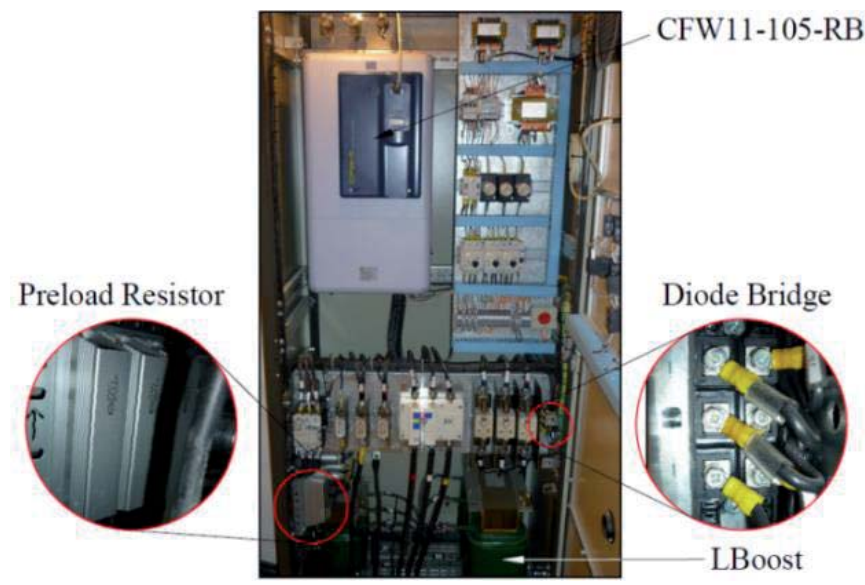

Fig. 19. Bidirectional power converter components.

\section{REGENERATIVE BRAKING}

\section{A. Motor Behavior}

The regenerative braking takes place when electric torque changes direction, but the velocity maintains the same orientation. This condition exists when the motor velocity is greater than synchronous velocity $v>v_{s}$.

An example of regenerative braking is shown in Figure 20, which exhibits three static torque versus speed characteristics maintaining $V / f$ constant. Considering the load torque constant, the motor speed can be varied by changing the operating point, for example: points 1 and 3 in figure 20. For the motor operating on point 1 , an abrupt frequency change will bring the motor to operate on point 2. Since the speed does not undergo abrupt changes, due to the motor inertia, the slip $s_{2}$, at point 2 , is negative $\left(s_{2}<0\right)$ developing a velocity $(v)$ above synchronous speed $\left(v_{s}\right)$ and allowing regeneration according to:

$$
s_{2}=\frac{v_{s}-v}{v_{s}}<0
$$

The linear induction motor equivalent circuit (Figure 4) shows that the branch $\mathrm{R}_{2}\left(\omega_{1} / \omega_{2}\right)$ is negative for this condition. The element $R_{2}\left(\omega_{1} / \omega_{2}\right)=R_{2} / \mathrm{s}$, according to the equivalent circuit of Figure 4 , consists of the sum of the secondary resistance $R_{2}$, due to the losses in copper, with the element that is the conversion of electrical into mechanical energy $R_{2}(1-\mathrm{s}) / \mathrm{s}$. With $s<0, R_{2}(1-\mathrm{s}) / \mathrm{s}$ becomes negative and the motor operates as a generator.

The maximal regenerated energy can be approximately obtained neglecting stator losses and flux leakage. In this case, the power transfer between rotor and stator is given by:

$$
P_{\text {rotor }}=\frac{V^{2} s}{R_{2}} \text {. }
$$

Considering $V / \omega_{s}=k$, follows equation (13). Equations (14) and (15) show the optimal relationship between supply frequency and motor speed.

$$
\begin{gathered}
P_{\text {rotor }}=k^{2} \frac{1}{R_{2}} \omega_{s}\left[\omega_{s}-\omega\right], \\
\frac{d}{d \omega_{s}} P_{\text {rotor }}=k^{2} \frac{1}{R_{2}}\left(2 \omega_{s}-\omega\right), \\
\frac{d}{d \omega_{s}} P_{\text {rotor }}=0 \rightarrow \omega_{s}=\frac{\omega}{2} .
\end{gathered}
$$

The energy can be utilized in auxiliary circuits, stored in batteries or capacitor banks or returned to grid. In this last case, the system needs to have a bidirectional power converter [8],[23],[26].

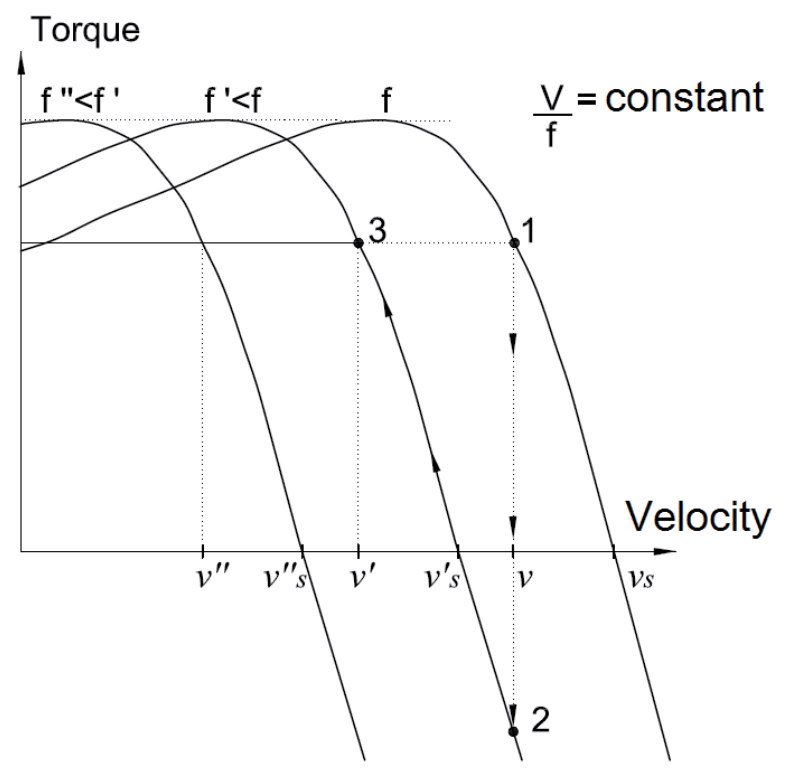

Fig. 20. Induction motor Torque x Speed curves.

\section{B. Converter Behavior}

A discussion about the converter behavior as motor or generator is easily explained when the analysis is done with the help of a single-phase equivalent circuit (Figure 21). 
$\mathrm{V}_{\mathrm{An}}$ is the converter output voltage that supplies the LIM. In Figure 22, when the current $I_{A}$ is in the first or fourth quadrants, the converter operates as inverter, feeding the LIM, which, in turn, behaves as a motor. In this case, voltage $\mathrm{V}_{\mathrm{An}}$ is advanced by an angle $\delta$ in relation to $\mathrm{E}_{\mathrm{A}}$. When $\mathrm{I}_{\mathrm{A}}$ is in the second or third quadrants, the converter operates as a rectifier supplying power to the LIM, which operates as generator to the DC link. In this case, $\mathrm{E}_{\mathrm{A}}$ is advanced $\delta$ in relation to $\mathrm{V}_{\mathrm{An}}$.

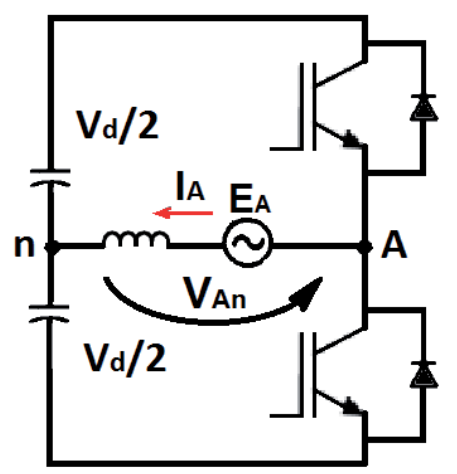

Fig. 21. Single-phase circuit with source $\mathrm{V}_{\mathrm{An}}$ and $\mathrm{I}_{\mathrm{A}}$ (LIM).

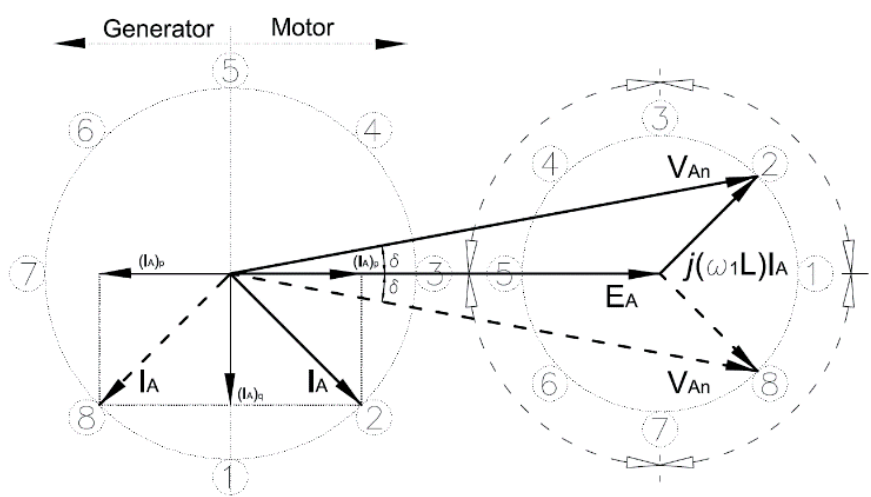

Fig. 22. Voltage phasorial diagram with source and load.

\section{EXPERIMENTAL RESULTS}

The following sessions, $\mathrm{A}$ and $\mathrm{B}$, report tests with the linear motor operating on a ramp and on a plan track, respectively.

\section{A. Tests on the Ramp}

Tests were carried out on a ramp (length $=6 \mathrm{~m}$ ), which allows variation of the declivity $(10 \%, 12.5 \%$ or $15 \%)$ changing the height $(h)$, as shown in Figures 23 and 24. Trapezoidal kinematic profiles were used (acceleration, rated speed and deceleration - Figure 25). TABLE II shows the variation of declivity $(h)$, transported mass $(m)$ and motor deceleration $(d)$ in each test performed. The DC link voltage and motor AC rms current for different conditions $\mathrm{m}$ and $\mathrm{h}$ were measured. The air gap $(g)$ is $8 \mathrm{~mm}$.

Changing $\mathrm{m}$ and $\mathrm{h}$ gradually increased the total stored energy. Higher values of the DC link voltage indicate that the capacitor bank of the intermediate mesh is being charged. This occur by current injection while the motor operates as a generator. The regeneration can also be observed measuring the DC link current with a Hall effect current probe (Fluke 80i-110s AC / DC). The current is negative during regeneration.

The results presented in Figures 26 through 31, show the operation of the motor with speed control $(V / f)$ and trapezoidal characteristics. Deceleration is obtained changing the frequency to lower values until complete stop vehicle. Figures 26 to 31 show, the motor current (dashed line) and voltage at DC link (solid line), during uphill and downhill operation. In all cases, an increase in the DC link voltage can be observed during deceleration.

Figures 26 and 27 indicate that during deceleration in downhill, the regenerated energy was low. For best results, the transported mass was changed to $1000 \mathrm{~kg}$, the deceleration is increased and the declivity was maintained at $10 \%$, according to TABLE II. The results presented in Figures 28 and 29 show the increased DC link voltage, featuring higher levels of energy regeneration.

To increase the total energy of the system, the declivity was set to $15 \%$ and the mass maintained at $m=1000 \mathrm{~kg}$. The test results are shown in Figures 30 and 31. These results show slightly higher voltage levels of the intermediate mesh. Even with more energy available, there was no more regeneration during braking.

The quantity of energy generated in the test shown in Figure 29, which has a deceleration rate of $d=16.16 \mathrm{~m} / \mathrm{s}^{2}$, was measured. Figure 32 shows that due to the short test track $(6 \mathrm{~m})$, the negative current (indicated in the figure) has low values of amplitude and duration $\sim 7.8 \mathrm{~s} \leq \mathrm{t} \leq \sim 8$.3s. The power and energy during this time interval can be seen in Figures 33 and 34, respectively.

The results of this section show that the system with more stored kinetic energy $\left(E_{c}=\left[m v^{2}\right] / 2\right)$ do not necessarily regenerate more energy during braking. The ability to harness this energy depends on the motor deceleration profile, according section VIII.
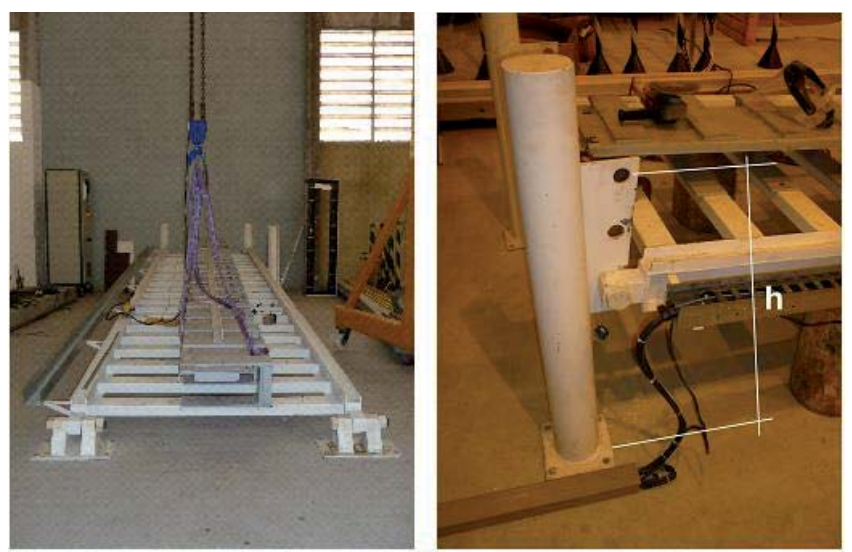

Fig. 23. Plataform used for regenerative braking tests.

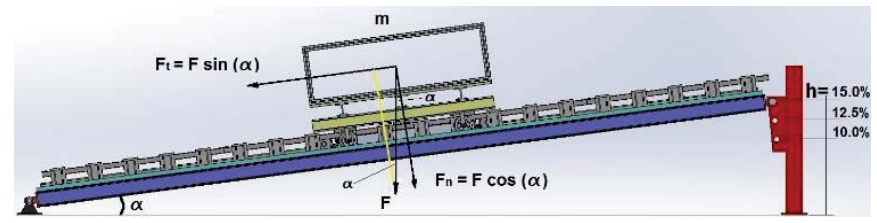

Fig. 24. System diagram. 


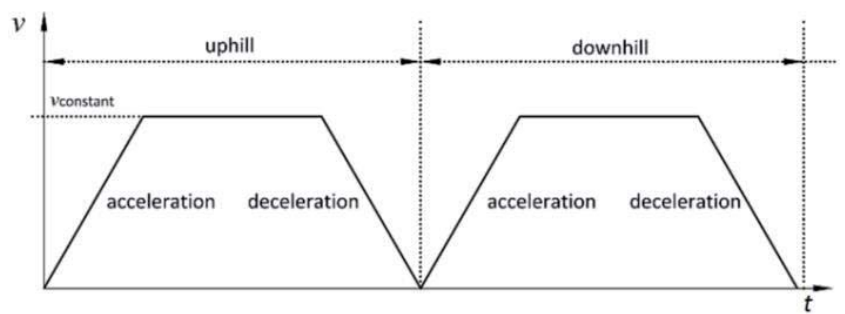

Fig. 25. Trapezoidal trajectory.

TABLE II

Test conditions on the ramp

\begin{tabular}{ccccc}
\hline Figure & $\begin{array}{c}\boldsymbol{h} \\
(\%)\end{array}$ & $\begin{array}{c}\boldsymbol{m} \\
(\boldsymbol{k g})\end{array}$ & $\begin{array}{c}\boldsymbol{d} \_ \text {uphill } \\
\left(\boldsymbol{m} / \mathbf{s}^{2}\right)\end{array}$ & $\begin{array}{c}\boldsymbol{d} \_ \text {downhill } \\
\left(\mathbf{m} / \mathbf{s}^{\mathbf{2}}\right)\end{array}$ \\
\hline Figure 26 & 10.0 & 450 & 0.37 & 1.72 \\
Figure 27 & 10.0 & 450 & 0.74 & 4.94 \\
Figure 28 & 10.0 & 1000 & 1.22 & 13.64 \\
Figure 29 & 10.0 & 1000 & 1.15 & 16.16 \\
Figure 30 & 15.0 & 1000 & 0.49 & 22.47 \\
Figure 31 & 15.0 & 1000 & 0.40 & 26.56 \\
\hline
\end{tabular}

1) Mass $=450 \mathrm{~kg}-$ Inclination $=10 \%$

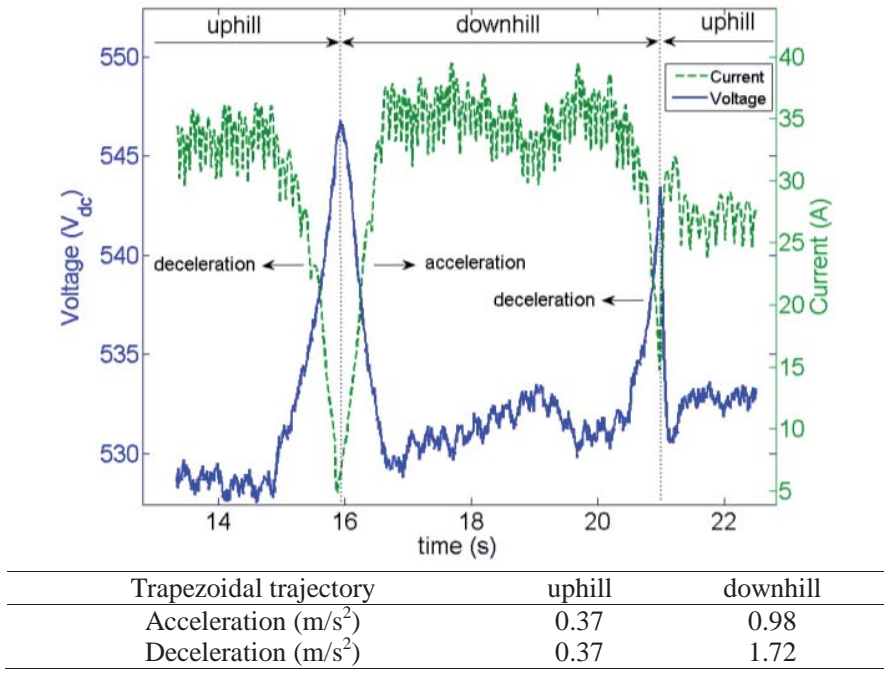

Fig. 26. DC link voltage and motor current $(450 \mathrm{~kg}-10 \%)$.

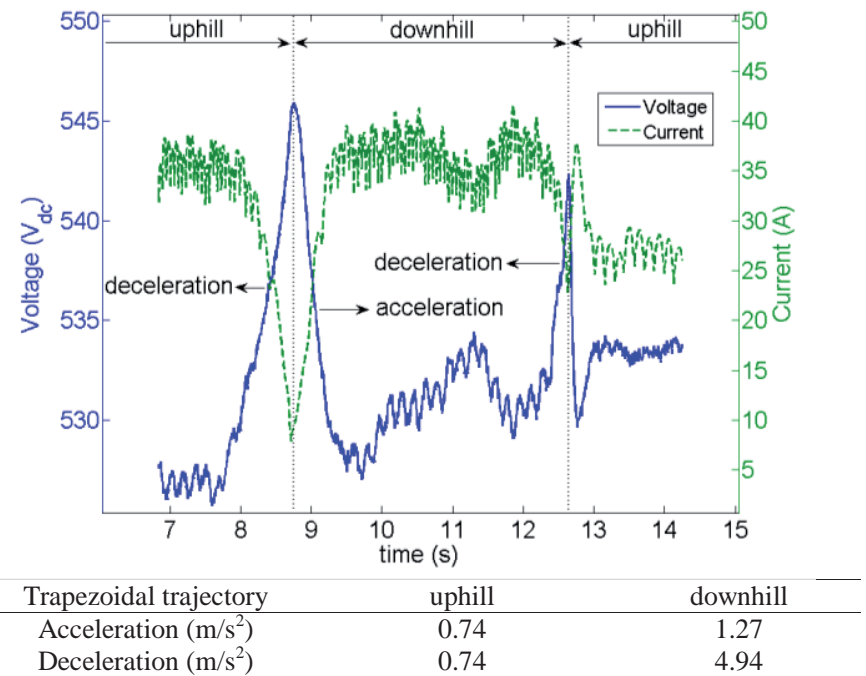

Fig. 27. DC link voltage and motor current $(450 \mathrm{~kg}-10 \%)$.
2) Mass $=1000 \mathrm{~kg}-$ Inclination $=10 \%$

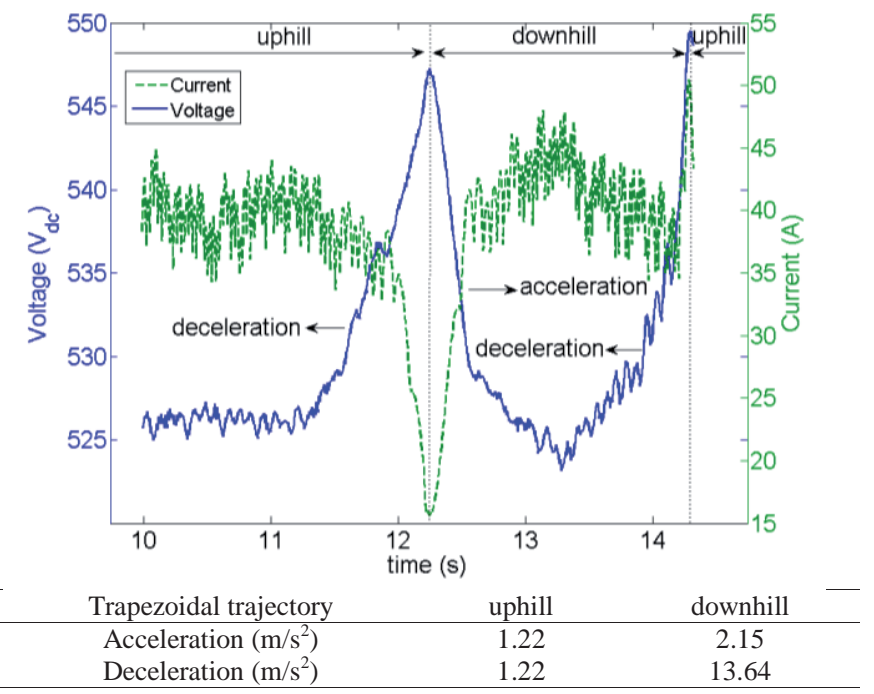

Fig. 28. DC link voltage and motor current $(1000 \mathrm{~kg}-10 \%)$.

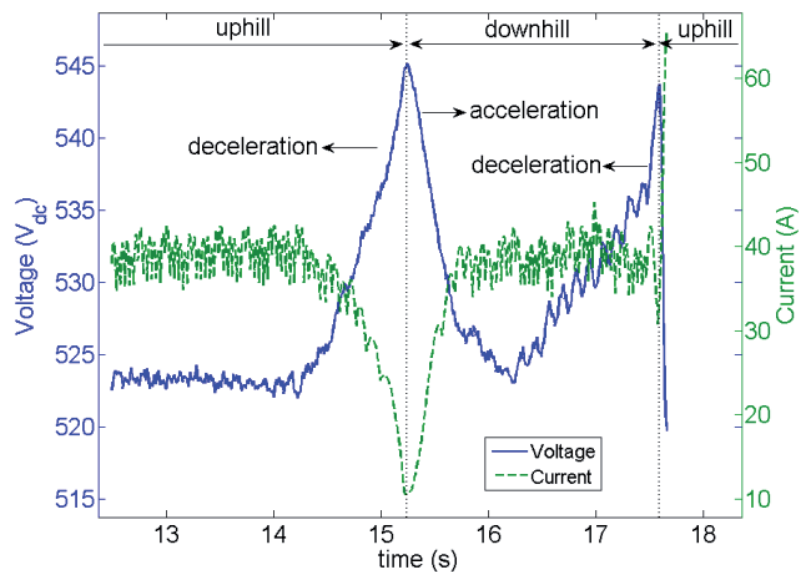

\begin{tabular}{ccc} 
Trapezoidal trajectory & uphill & downhill \\
\hline Acceleration $\left(\mathrm{m} / \mathrm{s}^{2}\right)$ & 1.15 & 1.67 \\
Deceleration $\left(\mathrm{m} / \mathrm{s}^{2}\right)$ & 1.15 & 16.16 \\
\hline
\end{tabular}

Fig. 29. DC link voltage and motor current $(1000 \mathrm{~kg}-10 \%)$.

3) Mass $=1000 \mathrm{~kg}-$ Inclination $=15 \%$

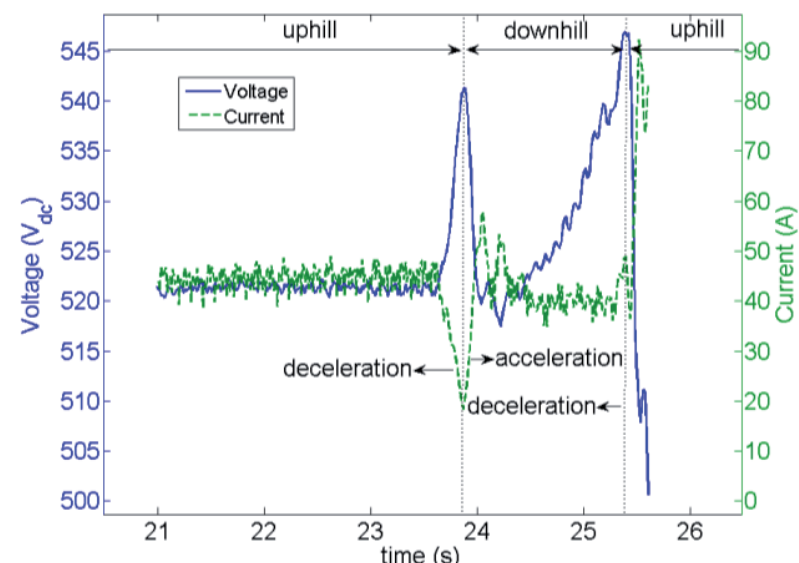

\begin{tabular}{ccc}
\hline Trapezoidal trajectory & uphill & downhill \\
\hline Acceleration $\left(\mathrm{m} / \mathrm{s}^{2}\right)$ & 0.49 & 11.23 \\
Deceleration $\left(\mathrm{m} / \mathrm{s}^{2}\right)$ & 0.49 & 22.47 \\
\hline
\end{tabular}

Fig. 30. DC link voltage and motor current $(1000 \mathrm{~kg}-15 \%)$. 


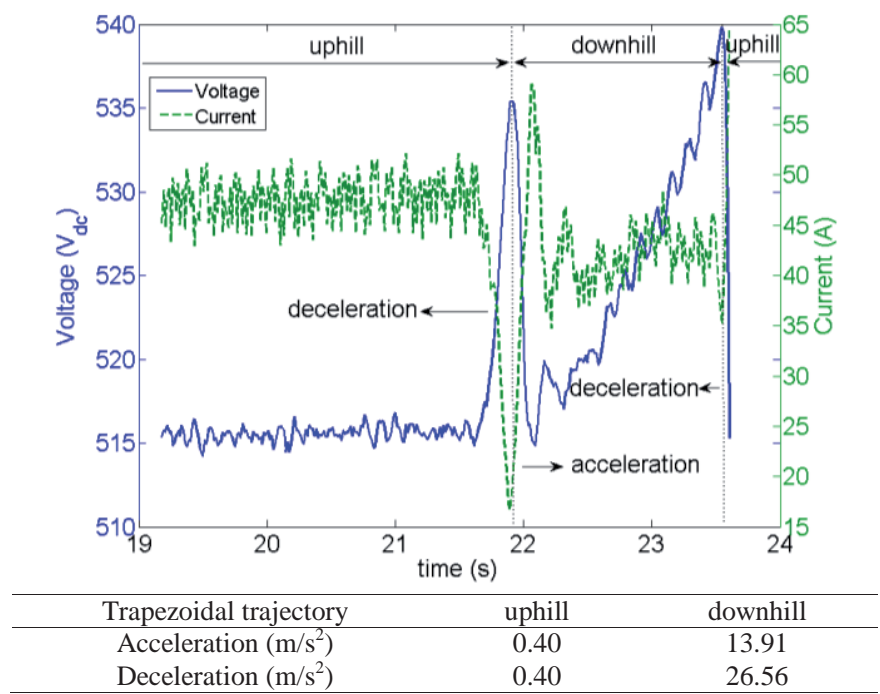

Fig. 31. DC link voltage and motor current $(1000 \mathrm{~kg}-15 \%)$.

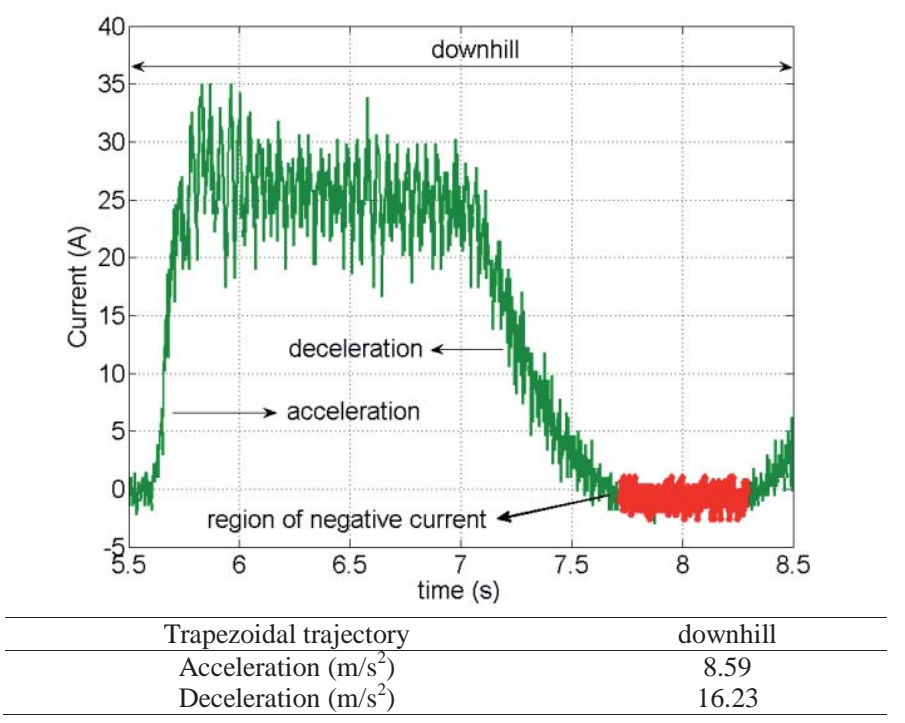

Fig. 32. Link DC current (1000kg - 15\%).

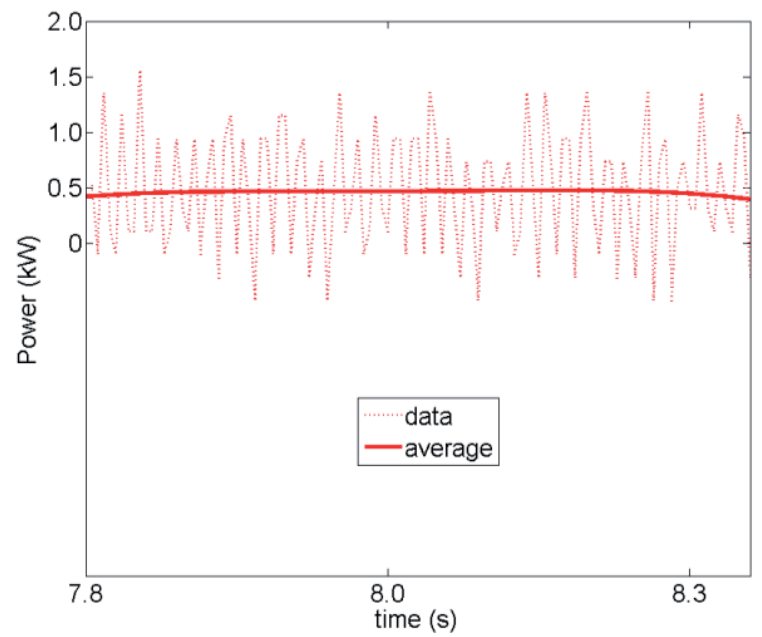

Fig. 33. Power supplied to the source during the braking interval (initial velocity $=2.92 \mathrm{~m} / \mathrm{s}$ and mass $=1000 \mathrm{~kg}$ ).

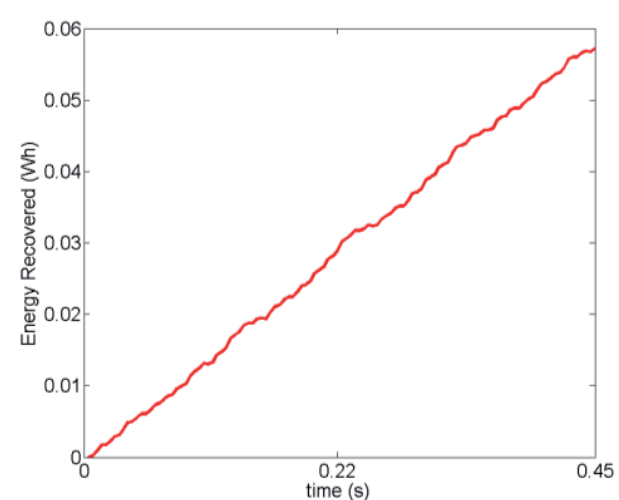

Fig. 34. Energy recovered during the braking interval.

\section{B. Tests on the Plan Track}

Tests on the plan track, Figure 35, were performed in a trajectory of $10.5 \mathrm{~m}$. A kinematic profile with trapezoidal characteristics such as acceleration, rated speed and deceleration, was imposed (vide Figure 36). The speed and deceleration time were varied, but the transported mass was fixed at $m=900 \mathrm{~kg}$.

In all tests, the motor air gap was maintained in $g=$ $8 \mathrm{~mm}$. TABLE III shows the characteristics of the tests. The results are shown in Figures 37 to 39.

With the decrease in the deceleration rate, there was a significant increase in the DC link voltage other than that intuitively expected. In fact, the analysis in Section VIII demonstrates that the maximal energy regeneration is given by (15), in other words, by decreasing the supply frequency in controlled steps of half the operational velocity.

The energy generated in the system can be returned to the grid, stored in a device or directly used by motor or load. A benefit of direct use is to reduce conversion losses and dispense auxiliary circuits.

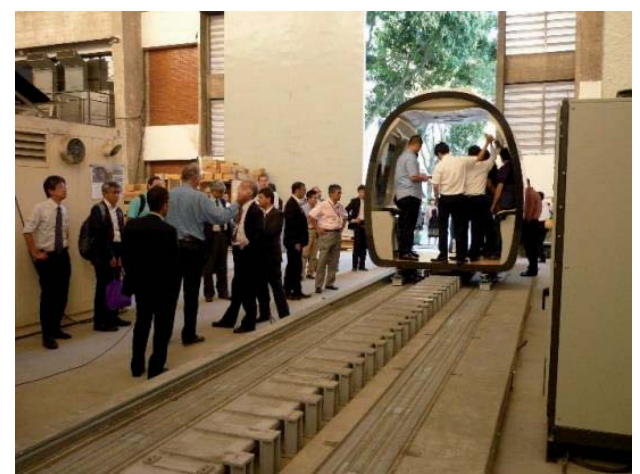

Fig. 35. Plan track.

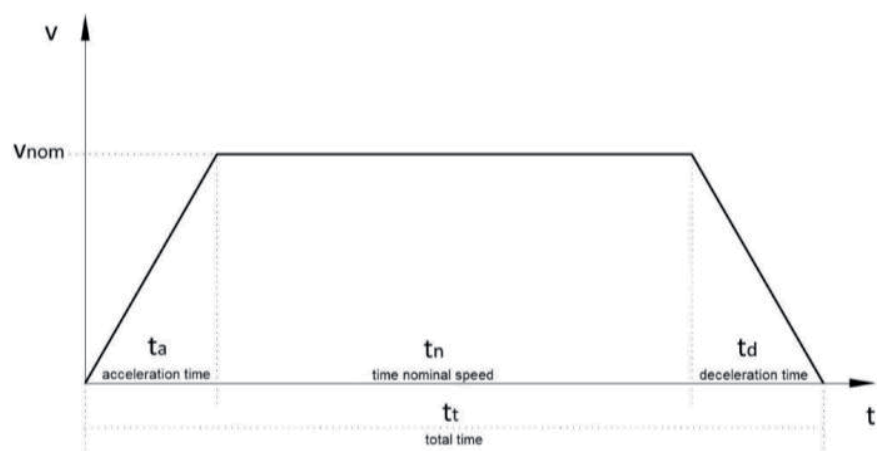

Fig. 36. Plan track trapezoidal trajectory. 
TABLE III

Test conditions on plan track

\begin{tabular}{cccc}
\hline Figure & $\begin{array}{c}\boldsymbol{h} \\
(\%)\end{array}$ & $\begin{array}{c}\boldsymbol{m} \\
(\boldsymbol{k} \boldsymbol{g})\end{array}$ & $\begin{array}{c}\boldsymbol{d} \\
\left(\boldsymbol{m} / \boldsymbol{s}^{\mathbf{2}}\right)\end{array}$ \\
\hline Figure 37 & 0.0 & 900 & 0.94 \\
Figure 38 & 0.0 & 900 & 0.36 \\
Figure 39 & 0.0 & 900 & 0.19 \\
\hline
\end{tabular}

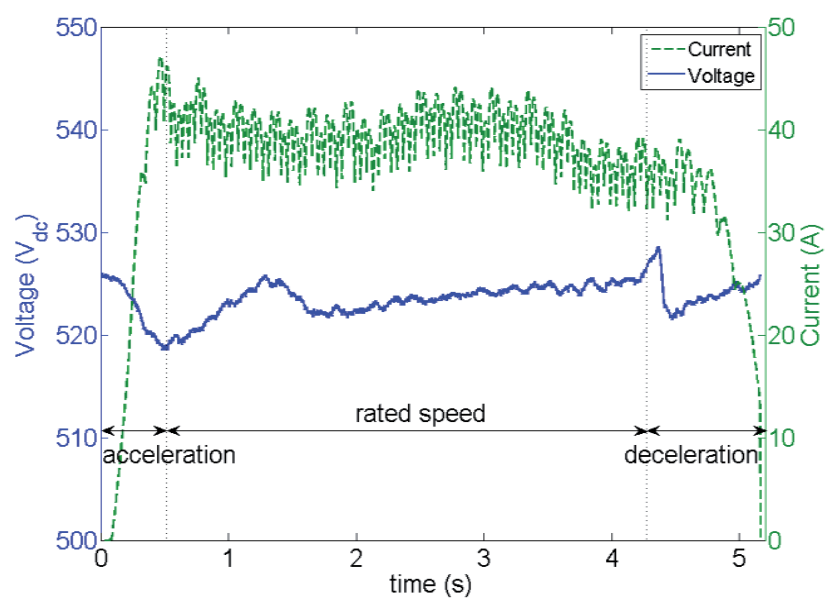

Fig. 37. DC link voltage and current motor.

$\left(m=900 \mathrm{~kg} ; v_{m}=1.31 \mathrm{~m} / \mathrm{s} ; d_{d} \cong 0.94 \mathrm{~m} / \mathrm{s}^{2}\right)$

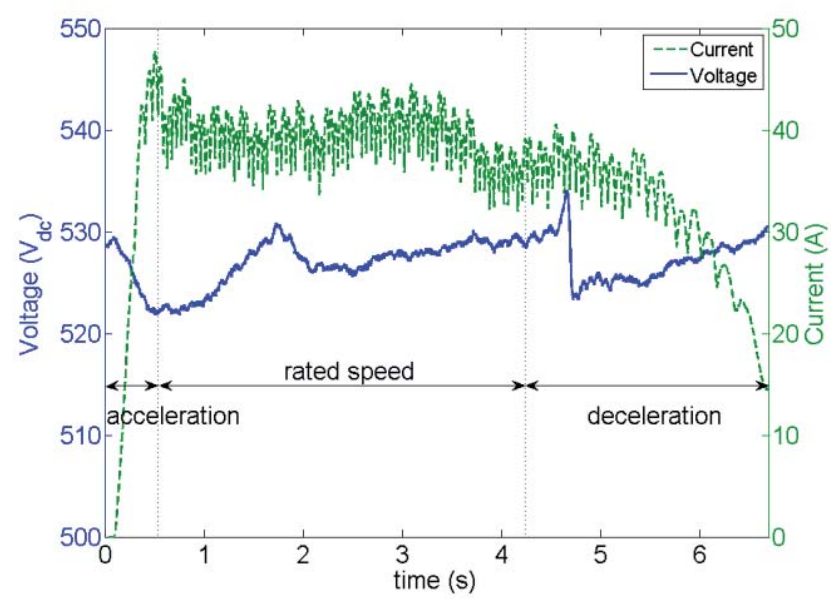

Fig. 38. DC link voltage and current motor.

$\left(m=900 \mathrm{~kg} ; v_{m}=0.89 \mathrm{~m} / \mathrm{s} ; d_{d} \cong 0.36 \mathrm{~m} / \mathrm{s}^{2}\right)$

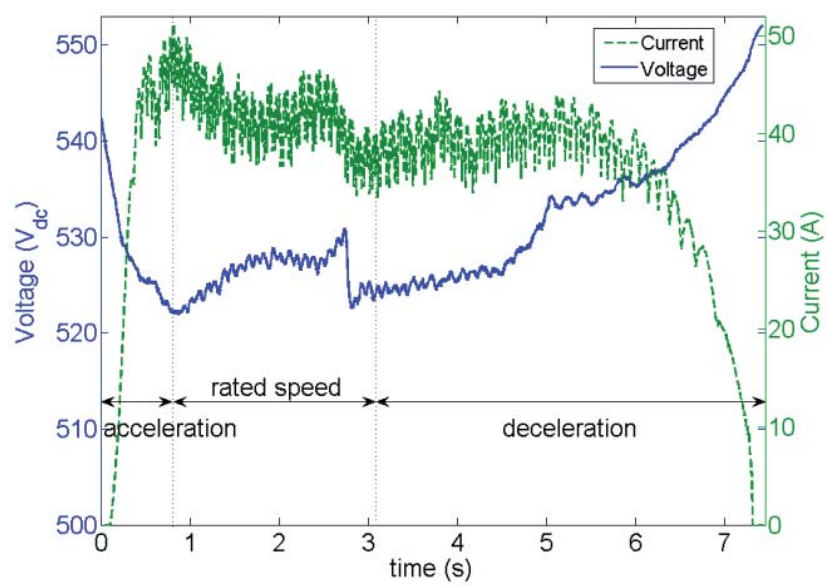

Fig. 39. DC link voltage and current motor.

$\left(m=900 \mathrm{~kg} ; v_{m}=0.82 \mathrm{~m} / \mathrm{s} ; d_{d} \cong 0.19 \mathrm{~m} / \mathrm{s}^{2}\right)$

\section{CONCLUSION}

The $V / f$ scalar control scheme allows the adequate motor control for low speed variation and enables the regenerative braking. The short $6 \mathrm{~m}$ test track allowed a first analysis of the regenerated energy. The $200 \mathrm{~m}$ long line, being presently constructed in UFRJ campus, will give the necessary conditions to verify the financial advantages of regenerative braking, to be reported after a period of operational experience.

The theoretical optimal deceleration is given by equation (15). However the braking profile must be established considering the kinematic conditions of operation, the comfort and safety of passengers.

\section{ACKNOWLEDGEMENT}

To BNDES, FAPERJ, CAPES (DINTER), CNPq and WEG for the financial support and to Dr. Ivan Chabu for the technical discussions.

\section{REFERENCES}

[1] IEA, "Energy Technology Perspectives. Scenarios and Strategies to 2050", 9 rue de la Fédération, 75739 Paris, Cedex 15, http://www.iea.org/, France, 2008.

[2] R. M. Stephan, R. Jr. Andrade, A. C. Ferreira, "Superconducting Light Rail Vehicle: a transportation solution for highly populated cities", IEEE Vehicular Technology Magazine, vol. 7, pp. 122-127, 2012.

[3] G. G. Sotelo, R. Jr. Andrade, D. H. Dias, A. C. Ferreira, F. Costa, O. J. Machado, R. A. H. Oliveira, M. D. A. Santos, R. M. Stephan, "Tests with One Module of the Brazilian Maglev-Cobra Vehicle", IEEE Transactions on Applied Superconductivity, vol. 99, pp. 1-1, 2013.

[4] M. P. Sucena, R. M. Stephan, "Modelo para gestão ambiental de sistemas de transporte urbano por levitação magnética com aplicação da teoria fuzzy", Journal of Transport Literature, vol. 6, pp. 152-179, 2012.

[5] D. H. N. Dias, E. S. Motta, G. G. Sotelo, R. de Andrade, R. M. Stephan, L. Kuehn, O. de Haas, L. Schultz, "Simulations and Tests of Superconducting Linear Bearings for a MAGLEV Prototype", IEEE Transactions on Applied Superconductivity, vol.19, no. 3, pp. 2120-2123, June 2009.

[6] G. G. Sotelo, R. de Andrade, A. C. Ferreira, "Test and Simulation of Superconducting Magnetic Bearings", IEEE Transactions on Applied Superconductivity, vol.19, no.3, pp.2083-2086, June 2009.

[7] A. M. Tavares, A. F. F. Filho, J. O. M. Osório, "Um estudo sobre a frenagem regenerativa de trens utilizando gerador linear de indução", Congresso Brasileiro de Automática-CBA, vol. 17, pp. 40-45, 2010.

[8] A. M. Tavares, Estudo Teórico e experimental sobre a frenagem regenerativa da máquina de indução linear, PhD thesis UFRGS, 2012.

[9] L. Yu, J.H. He, H. T. Yip, F. Du, Z. Q. Bo, J. Hu, "Simulation of regenerative braking in DC railway system based on MATLAB/Simulink", 45th 
International Universities Power Engineering Conference-UPEC, pp.1-5, Aug. 2010-Sept. 2010.

[10] K. Teramoto, K. Ohishi, S. Makishima, K. Uezono, S. Yasukawa, "Cooperative control of regenerative brake and mechanical brake for a two coach train", 38th Annual Conference on IEEE Industrial Electronics Society - IECON, pp.1707-1712, Oct. 2012.

[11] PI 1103525-0, Federal University of Rio de Janeiro UFRJ (BR/RJ), "Motor Linear Aplicado a Veículos de Transporte por Levitação Magnética”, July 2011.

[12] R. Nicolsky, R. M. Stephan, R. de Andrade, A. C. Ferreira, "The Brazilian Project for a Superconducting Magnetic Levitation Train", Proceedings of the XVI International Conference on Magnetically Levitated Systems and Linear Drives, vol. 1, pp. 179-182, Rio de Janeiro, 2000.

[13] R. M. Stephan, A. C. Ferreira, R. de Andrade, M. Moreira, L. G. Rolim, M. Neves, M. Rosário, O. J. Machado, R. Nicolsky, "A Superconducting Magnetic Levitation Train Prototype in Closed Loop Track", Proceedings of the XVIII International Conference on Magnetically Levitated Systems and Linear Drives, Shanghai, 2004.

[14] R. M. Stephan, E. David, O. Haas, "Maglev-Cobra: an Urban Transportation Solution Using HTSSuperconductors and Permanent Magnets", MAGLEV'2008, San Diego, 2008.

[15] R. M. Stephan, E. David, R. de Andrade, G. G. Sotelo, O. J. Machado, O. Haas, F. Werfel, "A Full-Scale Module of the Maglev-Cobra HTS-Superconducting Vehicle”, MAGLEV'2008, San Diego,2008.

[16] J. F. Gieras, Linear Induction Drives, Oxford Science Publications, New York, 1994.

[17] I. Boldea, S. A. Nasar, The Induction Machines Design Handbook, CRC Press, ISBN:978-1-4200-6668-5, 2010.

[18] Y. Guo, W. Xu, J. Zhu, H. Lu, Y. Wang, J. Jin, “Design and analysis of a linear induction motor for a prototype HTS maglev transportation system", International Conference on Applied Superconductivity and Electromagnetic Devices - ASEMD, pp.81-84, Sept. 2009.

[19] Q. Lu, Y. Li, X. Shen, Y. Ye, Y. Fang, Y. He, “Analysis of linear induction motor applied in low-speed maglev train", 15th International Conference on Electrical Machines and Systems - ICEMS, pp.1-6, Oct. 2012.

[20] T. Morizane, K. Tsujikawa, N. Kimura, "Control of Traction and Levitation of Linear Induction Motor Driven by Power Source With Frequency Component Synchronous With the Motor Speed", IEEE Transactions on Magnetics, vol. 47, no.10, pp.43024305, Oct. 2011.

[21] J. Duncan, "Linear induction motor-equivalent-circuit model", IEE Proc Electric Power Applications, vol. 130, PL B, No. 1, January 1983.

[22] E. R. Laithwaite, J. F. Eastham, H. R. Bolton, T. G. Fellows, "Linear motors with transverse flux", Proceedings of the Institution of Electrical Engineers, vol. 118, no. 12, pp.1761-1767, December 1971.

[23] S. J. Chapman, Electric Machine Fundaments, McGraw Hill, 2nd Edition, New York, USA, 1985.
[24] G. G. Sotelo, R. M. Stephan, P. J. Branco, R. de Andrade, "A didactic comparison of magnetic forces", International Journal of Electrical Engineering Education 48/2, pp. 117-129, March 2011.

[25] A. E. Fitzgerald, C. Kingsley, D. U. Stephen, Electric Machinery, McGraw-Hill Higher Education, 6th Edition, 2003.

[26] N. Mohan, T. M. Undeland, W. P. Robbins, Power Electronics: converters, applications, and design, John Wiley \& Sons, 2nd Edition, New York, USA, 1995.

[27] M. Barnes, Practical Variable Speed Drives and Power Electronics, Elsevier, 1st Edition, 2003.

\section{BIOGRAPHIES}

Roberto André Henrique de Oliveira, received the B.Sc. degree in Electrical Engineering in 2007. In 2013, he received the M.Sc. degree in Electrical Engineering from COPPE/UFRJ, where he is now pursuing the D.Sc. degree. From 2006 to 2012, he worked as engineer in the companies ThyssenKrupp and Otis with induction and synchronous motor drives applied to elevators. Since 2012, he has been working as electrical engineer in the development of the Maglev-Cobra vehicle (UFRJ). His main interests are in regenerative braking, control of electrical drives, power electronics and transportation systems.

Laércio Simas Mattos, was born in Juiz de Fora, MG, in 1972 and received the B.Sc. (2002) and M.Sc. (2005) degrees from the Federal University of Juiz de Fora, UFJF. Currently he is pursuing the doctor degree at COPPE/UFRJ, working in the development of the magnetically levitated vehicle MagLev-Cobra. He is Assistant Professor of the Federal Center of Technological Education of Minas Gerais, CEFET-MG. His working experience encompasses more than ten years of experience in the electrical engineering, electronics, power electronics and electrical circuits area.

Antônio Carlos Ferreira, received the B.Sc. and M.Sc. degrees from the Federal University of Rio de Janeiro, Rio de Janeiro, Brazil, in 1987 and 1991, respectively, and the Ph.D. degree from the University of Cambridge, Cambridge, U.K., in 1997, all in Electrical Engineering. Since 1989, he has been with the Graduate School of Engineering, Federal University of Rio de Janeiro, where he is currently an Associate Professor, teaching at both under-graduate and postgraduate levels. His main interests are power system and electrical machines.

Richard Magdalena Stephan, received the B.Sc. degree in electrical engineering from IME, Rio de Janeiro, in 1976, the M.Sc. degree in electrical engineering from COPPE/UFRJ in 1980, and the Dr.-Ing. degree in electrical engineering from Ruhr Universität Bochum, Germany, in 1985. Since 1978, he has been with the Department of Electrical Engineering, UFRJ. He spent a sabbatical leave at CEPEL in 1993. His main interests are in the fields of applications of superconductivity, control of electrical drives and power electronics. 